\title{
Case-control study of prolactin and placental lactogen in SGA pregnancies
}

\author{
Sharon R Ladyman1,2, Caroline M Larsen1, Rennae S Taylor3, David R Grattan1,2 and Lesley M E McCowan³ \\ ${ }^{1}$ Centre for Neuroendocrinology and Department of Anatomy, School of Biomedical Sciences, University of Otago, Dunedin, New Zealand \\ 2Maurice Wilkins Centre for Molecular Biodiscovery, Auckland, New Zealand \\ 3Department of Obstetrics and Gynaecology, Faculty of Medical and Health Science, University of Auckland, Auckland, New Zealand \\ Correspondence should be addressed to D R Grattan: dave.grattan@otago.ac.nz
}

\begin{abstract}
Prolactin and placental lactogens increase during pregnancy and are involved with many aspects of maternal metabolic adaptation to pregnancy, likely to impact on fetal growth. The aim of this study was to determine whether maternal plasma prolactin or placental lactogen concentrations at 20 weeks of gestation were associated with later birth of smallfor-gestational-age babies (SGA). In a nested case-control study, prolactin and placental lactogen in plasma samples obtained at 20 weeks of gestation were compared between 40 women who gave birth to SGA babies and 40 women with uncomplicated pregnancies and size appropriate-for-gestation-age (AGA) babies. Samples were collected as part of the 'screening of pregnancy endpoints' (SCOPE) prospective cohort study. SGA was defined as birthweight $<10$ th customized birthweight centile (adjusted for maternal weight, height, ethnicity, parity, infant sex, and gestation age) in mothers who remained normotensive. No significant differences were observed in concentrations of prolactin or placental lactogen from women who gave birth to SGA babies compared with women with uncomplicated pregnancies. However, a sexspecific association was observed in SGA pregnancies, whereby lower maternal prolactin concentration at 20 weeks of gestation was observed in SGA pregnancies that were carrying a male fetus $(132.0 \pm 46.7 \mathrm{ng} / \mathrm{mL}$ vs $103.5 \pm 38.3 \mathrm{ng} / \mathrm{mL}$, mean \pm S.D., $P=0.036$ Student's $t$-test) compared to control pregnancies carrying a male fetus. Despite the implications of these lactogenic hormones in maternal metabolism, single measurements of either prolactin or placental lactogen at 20 weeks of gestation are unlikely to be useful biomarkers for SGA pregnancies.
\end{abstract}

\section{Lay summary}

Early identification during pregnancy of small for gestational age (SGA) babies would enable interventions to lower risk of complications around birth (perinatal), but current detection rates of these at risk babies is low. Pregnancy hormones, prolactin and placental lactogen, are involved in metabolic changes that are required for the mother to support optimal growth and development of her offspring during pregnancy. The levels of these hormones may provide a measurable indicator (biomarker) to help identify these at risk pregnancies. Levels of these hormones were measured in samples from week 20 of gestation from women who went on to have SGA babies and control pregnancies where babies were born at a size appropriate for gestation age. Despite the implications of prolactin and placental lactogen in maternal metabolism, no significant differences were detected suggesting that single measures of either prolactin or placental lactogen at 20 weeks gestation are unlikely to be useful biomarker to help detect SGA pregnancies.

Keywords: $>$ small for gestational age $\quad$ prolactin $\quad$ human placental lactogen $\quad$ pregnancy 


\section{Introduction}

Small for gestational age (SGA) infants account for about $30-50 \%$ of non-anomalous still-born infants and those that survive have an increase in the risk for neurodevelopmental delays, and cerebral palsy (Baschat 2011, PMMRC 2018). Furthermore, the effects of being born SGA impacts on health as an adult, with increased risk of cardiovascular complications and diabetes in later life (Barker et al. 2007). Identification during pregnancy, leading to intervention and timely delivery has been reported to lead to a four-fold reduction in perinatal death and severe asphyxia (Lindqvist $\&$ Molin 2005). Identifying SGA before birth is difficult, however, and using population-based growth charts less than a quarter of all SGA babies are identified before birth (Wright et al. 2006). Using customized antenatal growth charts that take into account a range of factors including maternal weight, height, and ethnicity can improve antenatal identification of SGA infants, but even with this improvement detection rates are reported to be only around 50\% (Wright et al. 2006, Roex et al. 2012). Recent analysis of a multi-centre cohort study (SCOPE) has identified key clinical variables at 15 weeks that are associated with later development of SGA (McCowan et al. 2013). In that study, only one quarter $(24.5 \%)$ of all SGA infants were identified before birth, highlighting the need to have improved methods for detecting SGA during pregnancy (McCowan et al. 2013). As indicated in McCowan et al. (2013), the key next step for the development of a personalized algorithm for prediction of SGA is the identification of reliable biomarkers that can be combined with clinical risk factors (McCowan et al. 2013).

One of the key hormones associated with pregnancy is prolactin. While prolactin is thought of primarily as a lactation hormone (Trott et al. 2012), it has also been implicated in a wide range of other functions (Bole-Feysot et al. 1998, Grattan 2015), particularly during pregnancy (Grattan \& Le Tissier 2015). Prolactin concentrations increase progressively throughout pregnancy in women (Tyson et al. 1972, Grattan 2001, Romero et al. 2017, Aghaeepour et al. 2018) and the placenta also contributes the closely related human placental lactogen (hPL (CSH1), or chorionic somatomammotropin) as an additional source of circulating hormone that can activate the prolactin receptor. Human placental lactogen is secreted from the syncytiotrophoblast starting at 6 weeks of gestation and then increasing to extremely high levels as gestation advances (Braunstein et al. 1980). Indeed, recent proteomic studies of human pregnancy blood samples have identified prolactin in the top $1 \%$ of proteins showing increased expression during pregnancy

https://raf.bioscientifica.com

https://doi.org/10.1530/RAF-21-0020 Published by Bioscientifica Ltd
(Romero et al. 2017, Aghaeepour et al. 2018), with hPL also as one of the highest induced proteins (Aghaeepour et al. 2018). Prolactin and hPL play an important role in mediating the maternal metabolic adaptations that help to establish a positive energy balance to meet the demands of fetal growth and also to prepare for subsequent demands of lactation (Augustine et al. 2008, Grattan \& Kokay 2008, Newbern \& Freemark 2011, Grattan \& Le Tissier 2015). These adaptations ensure appropriate glucose and amino acid availability to the fetus (Handwerger 1991). Prolactin may also have a more direct role in fetal growth by influencing trophoblast invasion in early pregnancy (Stefanoska et al. 2013), which when impaired, has been associated with SGA pregnancies (Knofler 2010). In animal models, experimental suppression of placental lactogenic hormones is associated with fetal growth restriction (Lee et al. 2015). Reduced expression of genes for $h P L(C S H 1)$ and the placental growth hormone variant $(G H-\mathrm{V})$ have been observed in terms of placentas associated with SGA newborns (Mannik et al. 2010), suggesting that secretion of these placental hormones may be compromised when fetal growth is impaired. Changes in expression of imprinted genes that control $h P L$ expression (John 2013) have also been associated with changes in fetal growth (Jensen et al. 2014, Janssen et al. 2016). Similarly, animal models involving manipulation of these placental regulatory genes also result in changes in fetal growth (Tunster et al. 2016). These data highlight the potential for placental hormones to serve as biomarkers of impaired fetal growth. Collectively, these data are consistent with the hypothesis that changing levels of circulating hormones that act through the prolactin receptor, including prolactin and growth hormone from the maternal pituitary (and also decidua), and hPL (and to a lesser extent GH-V) from the placenta, impact on fetal growth and could potentially serve as biomarkers of impaired fetal growth. In our previous work, we showed that while circulating GH-V correlated with fetal growth in large for gestational age babies, there was no detectable deficit in SGA pregnancies (Liao et al. 2016). The aim of the current study was to investigate if hPL or pituitaryderived prolactin levels were reduced at 20 weeks of gestation in pregnancies that resulted in birth of a SGA baby.

\section{Methods}

\section{Study design}

The participants were healthy, nulliparous women with singleton pregnancies who were recruited in Auckland, New Zealand, to be included in the multi center 'screening of pregnancy endpoints' (SCOPE) study. The SCOPE study 
was a prospective, multicentre international screening study which aimed to develop screening tests to predict preeclampsia, SGA infants, and spontaneous preterm births. Ethics approval and consent to participate was obtained from local ethics committees, including New Zealand (AKX/02/00/364) and all women provided written informed consent. Detailed methods of the SCOPE study are described elsewhere (McCowan et al. 2010). For the current study, 40 case and 40 control samples were randomly selected from the participants who were recruited in Auckland, New Zealand, (total of 1296 uncomplicated AGA pregnancies and 159 normotensive SGA pregnancies) and who had a 20-week plasma specimen.

For the current investigation, plasma samples obtained at 20 weeks of gestation were used. Following birth (usually within $72 \mathrm{~h}$ of giving birth), pregnancy outcome data and infant measurements were recorded by research midwives. An SGA outcome was conventionally defined as a birthweight of less than the tenth customised centile, adjusted for maternal height, booking weight, ethnicity, sex of infant, and gestation at birth. The control group in this nested case-control study comprised of 40 women with singleton, uncomplicated pregnancies who delivered babies with birthweight $>10$ th customised centile, while the SGA group comprised 40 women with singleton, normotensive pregnancies who delivered SGA babies. The number of 40 per group was determined based on power analysis (for an effect size of 0.8 ) based on unforeseen, preliminary data obtained from another study using samples from the SCOPE study.

\section{Assays}

Prolactin and placental lactogen concentrations were measured in duplicate in 20 weeks of gestation maternal plasma samples using commercially available ELISA assays (human prolactin ELISA (25-PROHU-E01) and human placental lactogen ELISA (20-HPLHU-E01) both from Alpco Diagnostics). Assays were performed as described in the manufacturer's instructions. For the hPL assay, the intraassay CV was $2.8 \%$ and interassay CV was $13.2 \%$. For the prolactin assay, the intraassay $\mathrm{CV}$ was $3.2 \%$ and the interassay CV was $5.1 \%$. For each assay plate, both control and case studies were included.

\section{Statistical analysis}

All hormone data was analyzed for normality using the D'Agostino and Pearson normality test. When data was normally distributed, a Student's $t$-test was used to assess the significance between groups, whereas when data was not normally distributed, a Mann-Whitney nonparametric test was used. The Mann-Whitney test was used for human placental lactogen analysis of all combined samples and samples from mothers carrying female fetuses; and a twotail Student's $t$-test was used for the prolactin analysis along with analysis for human placental lactogen in samples from mothers carrying male fetuses. Since the hypothesis was that low lactogenic hormone activity would be associated with SGA pregnancies, we also analyzed the data using a one-tail test. Previous work has suggested fetal sex-specific association of low $\mathrm{hPL}$ and reduced fetal growth (Lagerstrom et al. 1990), therefore, the data was also analyzed based on fetal sex. Each group was assessed for outliers using the ROUT outlier test. Only one sample from the control group of the hPL data was removed due to testing positive as an outlier (extremely high at $13.43 \mathrm{ng} / \mathrm{mL}$ ), however, the outcome of the statistical analysis did not differ with or without the inclusion of this value (with: $P=0.7736$, without: $P=0.7736$ using two-tailed Mann-Whitney tests). Statistical differences in the study population characteristics between control pregnancies and SGA pregnancies were analyzed with Student's $t$-test for continuous variables and with chi-square tests for categorical variables. For hormone data, all values were expressed as mean \pm S.D., and for the study population characteristics, continuous variables are expressed as mean (S.D.) while categorical variables are expressed as numbers (percentage).

\section{Results}

Maternal characteristics and pregnancy outcomes for the normotensive SGA and uncomplicated pregnancy groups are detailed in Table 1. There were no differences between groups for any maternal characteristics. SGA cases were delivered earlier than controls $(P=0.03)$.

No significant differences were detected in maternal plasma placental lactogen or prolactin concentrations between the uncomplicated pregnancy and SGA groups (placental lactogen: $P=0.7736$ two-tailed Mann-Whitney tests, prolactin: $P=0.1164$ two-tailed $t$-test) (Fig. 1). When specifically investigating the hypothesis that low lactogenic hormone activity would be associated with SGA pregnancies, there was no statistically significant difference in prolactin concentrations in pregnancies that went on to have a SGA infant compared to those with uncomplicated pregnancies $(P=0.058)$. To determine whether any trend might become more pronounced with more severe SGA, the data was further examined using only the samples from more extreme SGA cases ( $<5$ th centile). No significant

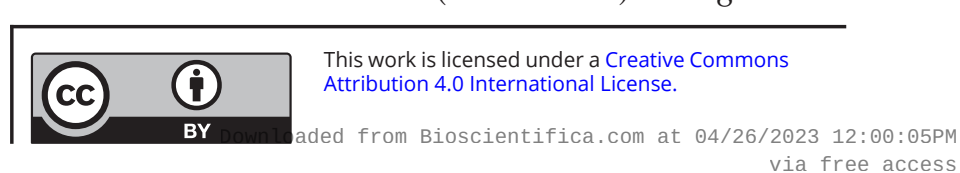


Table 1 Study population characteristics at 15 weeks and pregnancy outcomes. Results expressed as $n$ (\%) or mean (s.D.). Continuous variables: $t$-test; categorical variables: chi-square or Fisher's exact test.

\begin{tabular}{|c|c|c|c|}
\hline & Normotensive SGA $(n=40)$ & Uncomplicated pregnancy $(n=40)$ & P value \\
\hline \multicolumn{4}{|l|}{ Maternal details at 15 weeks } \\
\hline Maternal age (y) & $31.6 \pm 4.4$ & $31.3 \pm 4.4$ & 0.78 \\
\hline Caucasian ethnicity & $37(93 \%)$ & 37 (93\%) & 1.0 \\
\hline Primigravid & $29(73 \%)$ & $29(73 \%)$ & 1.0 \\
\hline Single & $2(5 \%)$ & 0 & 0.49 \\
\hline No paid employment & 0 & $3(7.5 \%)$ & 0.24 \\
\hline Socioeconomic index & $51 \pm 12$ & $48 \pm 12$ & 0.29 \\
\hline Smoker & $1(2.5 \%)$ & $1(2.5 \%)$ & 1.0 \\
\hline BMI category (kg/m²) & & & 0.58 \\
\hline$<24.9$ & $26(65 \%)$ & $25(62.5 \%)$ & \\
\hline $25-29.9$ & $10(25 \%)$ & $13(32.5 \%)$ & \\
\hline$\geq 30.0$ & $4(10 \%)$ & $2(5 \%)$ & \\
\hline Systolic BP (mmHg) & $106 \pm 10$ & $107 \pm 9$ & 0.82 \\
\hline Diastolic BP (mmHg) & $63 \pm 9$ & $66 \pm 8$ & 0.19 \\
\hline 15-week extreme exercise (yes) & $1(2.5 \%)$ & 0 & 1.0 \\
\hline Gestation at sampling (wks) & $19.9 \pm 0.6$ & $19.9 \pm 0.7$ & 0.86 \\
\hline \multicolumn{4}{|l|}{ Pregnancy outcomes } \\
\hline Birthweight (g) & $2710 \pm 398$ & $3506 \pm 353$ & $<0.001$ \\
\hline Sex of baby (girl) & $18(45 \%)$ & $20(50 \%)$ & 0.82 \\
\hline Gestational age at delivery (weeks) & $39.2 \pm 2.4$ & $40.2 \pm 1.1$ & 0.03 \\
\hline Customised birthweight centile & $5.7 \pm 2.6$ & $45.9 \pm 23.7$ & $<0.001$ \\
\hline Preterm births (<37 weeks) & $6(15 \%)$ & 0 & 0.08 \\
\hline Neonatal unit admission & $8(20 \%)$ & $2(5 \%)$ & 0.09 \\
\hline \multicolumn{4}{|l|}{ Specimen analyzes at 20 weeks* } \\
\hline Prolactin $(\mathrm{ng} / \mathrm{mL})$ & $112.6 \pm 44.9$ & $128.2 \pm 43.2$ & $0.058(0.116)$ \\
\hline Human placental lactogen $(\mathrm{mg} / \mathrm{mL})$ & $2.46 \pm 0.74$ & $2.64 \pm 1.84$ & $0.464(0.774)$ \\
\hline
\end{tabular}

*Specimen analyzes are expressed as mean (S.E.M.) and $P$ values for both one-tailed and two-tailed statistical testing is given, with the latter being in brackets.
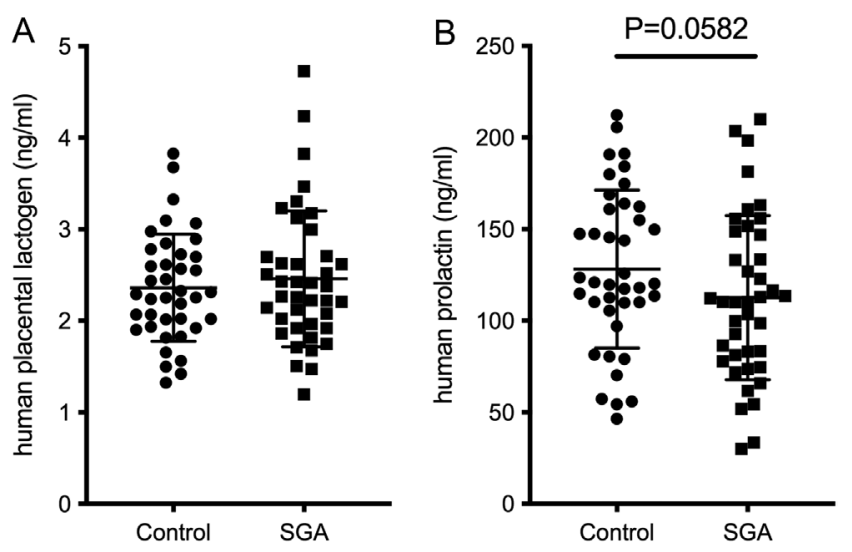

Figure 1 Placental lactogen (A) and prolactin concentrations (B) in maternal plasma samples collected from pregnant women at 20 weeks of gestation who went on to have babies of normal birth weight (control, $n=$ 40 ) or small for gestational age (SGA, <10th centile, $n=40$ ). One sample was removed from the control placental lactogen group as it was tested to be an outlier. Placental lactogen, $P=0.3868$ (one-tailed Mann-Whitney nonparametric test as data were not normally distributed (SGA group $P<$ 0.05 D'Agostino and Pearson normality test)). Human prolactin, $P=0.0582$ (Student's one-tailed $t$-test). Data shown as mean \pm S.D. differences were found between control and SGA groups in this further analysis (Fig. 2).

No differences were seen at week 20 of gestation between the uncomplicated pregnancy and SGA groups in maternal hPL and prolactin concentrations when the fetus was female (placental lactogen: $P=0.1258$ twotailed Mann-Whitney tests, prolactin: $P=0.9586$ twotailed $t$-test) (Fig. 3). When the fetus was male, maternal prolactin concentrations were significantly lower at 20 weeks of gestation in SGA pregnancies compared to uncomplicated pregnancies (prolactin: $P=0.0361$ twotailed $t$-test) while maternal hPL was similar in both groups (placental lactogen: $P=0.1749$ two-tailed MannWhitney tests) (Fig. 3).

\section{Discussion}

In current clinical practices less than $50 \%$ of pregnancies with SGA infants are usually detected before birth. Early detection of SGA pregnancies and timely delivery improves outcomes and is , therefore, an important research priority. The aim of the present study was to determine whether

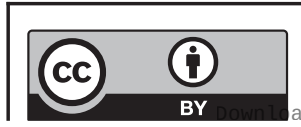

This work is licensed under a Creative Commons Attribution 4.0 International License. 

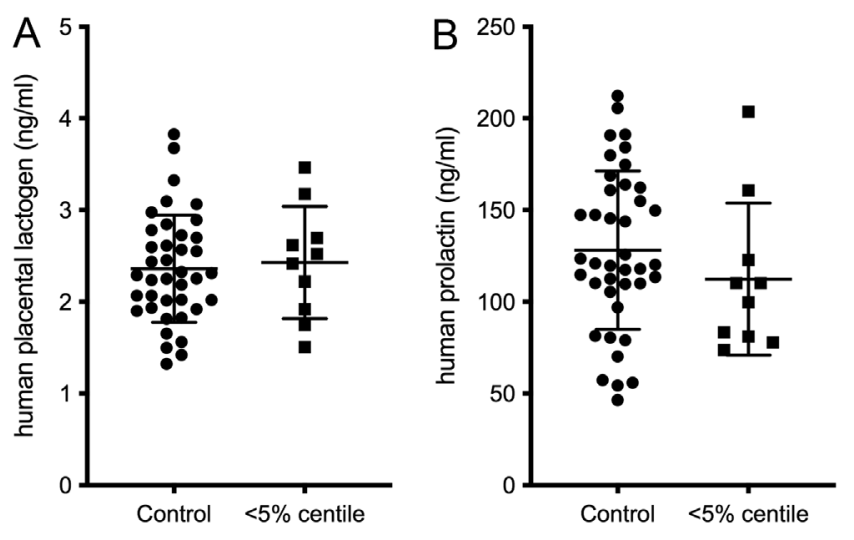

Figure 2 Placental lactogen and prolactin concentrations in maternal plasma samples collected from pregnant women at 20 weeks of gestation who went on to have babies of normal birth weight (control, $n=40$ ) or SGA ( $<5$ thcentile, $n=10)$. One sample was removed from the control placental lactogen group as it was tested to be an outlier. Human placental lactogen $P=0.75$, Student's $t$-test. Human prolactin $P=0.30$, Student's $t$-test. Data shown as mean \pm s.D.

either prolactin or placental lactogen might serve as a useful biomarker to help predict SGA infants.

Lactogenic hormones such as prolactin and placental lactogen are markedly increased during pregnancy, and play important roles in maternal adaptation to support the growing fetus (Augustine et al. 2008, Newbern \& Freemark 2011). As well as mammary gland development, prolactin receptor activation during pregnancy, by either prolactin or placental lactogens, has been implicated in important roles in maternal metabolic adaptations, including induction of pregnancy-specific glucose regulation to direct glucose towards the fetus (Sorenson \& Brelje 1997, Baeyens etal. 2016), and increasing food intake to meet the energy demands of the growing fetus and prepare for lactation (Augustine \& Grattan 2008, Augustine et al. 2008). Prolactin action in the fetus is also involved in a range of developmental and growth functions (Winters et al. 1975, Hauth et al. 1978, Pullano et al. 1989). Therefore, we hypothesized that inadequate prolactin and/or placental lactogen during pregnancy may be associated with pregnancies with SGA infants.

We found a trend $(P=0.058)$ for lower prolactin concentrations at 20 weeks of gestation in pregnant women who went on to have SGA babies ( $<10$ th centile), however, this potential relationship was not apparent in more extreme SGA $(<5$ th centile) and lends strength to the conclusion that a single measurement of prolactin at 20 weeks of gestation is not a useful biomarker of SGA. When the data was analyzed based on the sex of the fetus, we found a significant reduction in maternal prolactin concentrations in SGA pregnancies compared to uncomplicated pregnancies when the fetus was male. However, there was
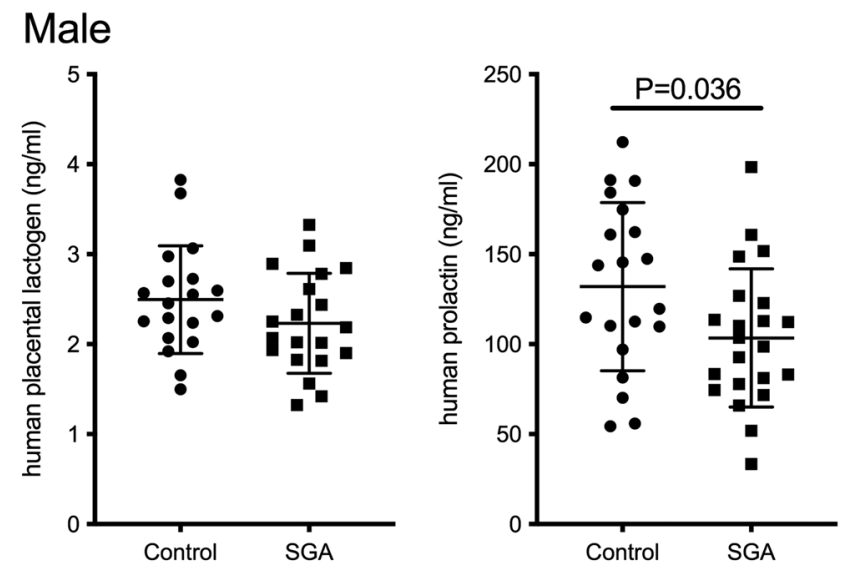

\section{Female}
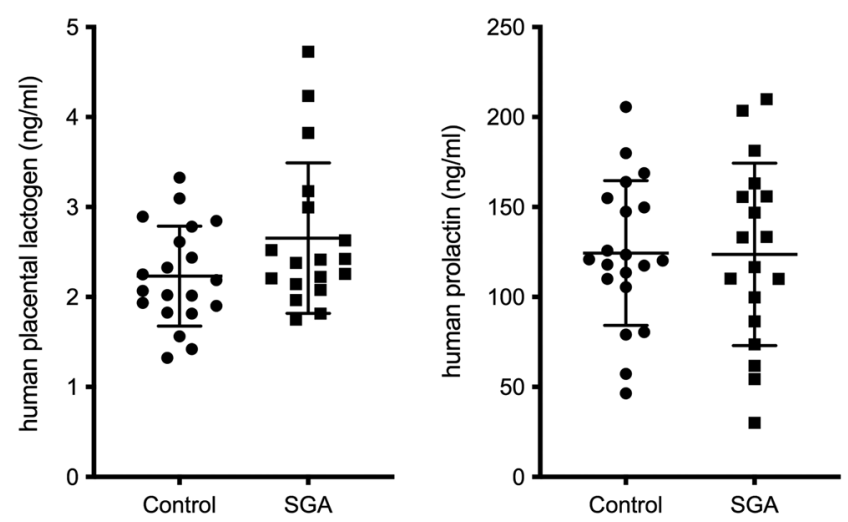

Figure 3 Placental lactogen (hPL) and prolactin concentrations in plasma samples from pregnant women carrying boys (top) or girls (bottom). Plasma samples were collected at 20 weeks of gestation from women who went on to have babies of normal birth weight (control, boys: $n=20$, girls: $n=20$ ) or SGA, boys: $n=22$, girls: $n=18$ ). Boys: hPL $P=0.164$, prolactin $P=0.036$, Student's $t$-test, Girls: hPL $P=0.126$, Mann-Whitney nonparametric test as data were not normally distributed (SGA group $P<$ 0.05 D'Agostino and Pearson normality test)), prolactin $P=0.959$,

Student's $t$-test. Data shown as mean \pm S.D.

still quite an overlap between the prolactin concentrations in these two groups, suggesting that maternal prolactin concentrations by itself is unlikely to be a useful biomarker per se even in pregnancies carrying male fetuses. Whether it might contribute to a wider risk score, associated with assessment of key clinical variables (McCowan et al. 2013) requires further investigation. Overall, there was no correlation between plasma prolactin concentrations at 20 weeks and birth weight (data not shown). Whether plasma prolactin may be a useful biomarker of SGA at other time points during pregnancy cannot be ruled out by these data. At term, hPL has been significantly associated with infant birth weight (Janssen et al. 2016) and potentially this relationship would be detectable at an earlier time, thus future work investigating time points between 20 weeks and term would be warranted. 
Previous work has indicated that in pregnancies carrying female fetuses, maternal hPL is lower in SGA pregnancies compared to uncomplicated controls (Lagerstrom et al. 1990). We did not observe this difference in hPL and the reasons for this inconsistency between previous work and the current study are unknown. Previous work was a prospective cohort study and hence their SGA group size was smaller than the current study. It should be noted, however, that the difference in group size between our female SGA group $(n=18)$ and the previous study $(n=11)$ was not large. It is also possible that the definition of SGA in this current study and that of SFD (small for date) for the previous study are not comparable given the 30 year lapse in time between studies.

Our sample size was only 40 cases and 40 controls. Based on the apparent effect size and the high variability, we observed for both hormones; a post hoc power analysis indicated that a larger study with at least 95 patients per group would be required to determine whether the observed trend was significant when data was not analyzed by fetal sex. Within such a larger study, analysis of clinical and other biomarker variables that could be assessed alongside prolactin concentrations may strengthen the predictive value, especially for male fetuses. Our study only assessed one timepoint, and future work should also assess the relevance of other time points in pregnancy that may be of use for aiding diagnosis of SGA.

Overall, while maternal prolactin concentrations did tend to be lower in SGA pregnancies, there was great variation and overlap of prolactin concentrations in both groups. A significant sex-specific association was observed, with SGA pregnancies carrying male fetuses having lower maternal prolactin concentrations compared to uncomplicated pregnancies carrying male fetuses. Our work suggests that neither prolactin nor placental lactogen at 20 weeks gestation are likely to be useful biomarkers for SGA, however this does not rule out their potential to be useful at a different time point of pregnancy.

\section{Declaration of interest}

The authors declare that there is no conflict of interest that could be perceived as prejudicing the impartiality of the research reported.

\section{Funding}

This work was funded by the New Zealand Health Research Council. This funding body had no role in the design of the study, collection, analysis, and interpretation of the data, nor in the writing of this manuscript.

\section{Ethics approval and consent to participate}

Ethics approval was obtained from local ethics committees, including New Zealand (AKX/02/00/364) and all women provided written informed consent.
Availability of data and material

The data sets from this manuscript is available by reasonable request from the corresponding author.

\section{Author contribution statement}

$C L, R S T, D R G$, and L M E M were involved in the conceptualization of the study and the design of the work. S R L analyzed the data and wrote the manuscript. SR L, RST, D R G, and L M E M contributed to the interpretation of the data and edited the manuscript. All authors have read and approved the manuscript.

\section{Acknowledgements}

The authors would like to thank the pregnant women who participated in the SCOPE study; Ms Pene Knowles for performing the hormone assays, and Dr Jaijus Pallippadan Johny for statistical advice. The authors also thank the reviewer for the useful suggestion to analyze the data by fetal sex.

\section{References}

Aghaeepour N, Lehallier B, Baca Q, Ganio EA, Wong RJ, Ghaemi MS, Culos A, El-Sayed YY, Blumenfeld YJ, Druzin ML, et al. 2018 A proteomic clock of human pregnancy. American Journal of Obstetrics and Gynecology 218 347.e1-347.e14. (https://doi. org/10.1016/j.ajog.2017.12.208)

Augustine RA \& Grattan DR 2008 Induction of central leptin resistance in hyperphagic pseudopregnant rats by chronic prolactin infusion. Endocrinology 149 1049-1055. (https://doi.org/10.1210/ en.2007-1018)

Augustine RA, Ladyman SR \& Grattan DR 2008 From feeding one to feeding many: hormone-induced changes in bodyweight homeostasis during pregnancy. Journal of Physiology 586 387-397. (https://doi. org/10.1113/jphysiol.2007.146316)

Baeyens L, Hindi S, Sorenson RL \& German MS 2016 beta-Cell adaptation in pregnancy. Diabetes, Obesity and Metabolism $\mathbf{1 8}$ (Supplement 1) 63-70. (https://doi.org/10.1111/dom.12716)

Barker DJ, Osmond C, Forsen TJ, Kajantie E \& Eriksson JG 2007 Maternal and social origins of hypertension. Hypertension $\mathbf{5 0} 565-571$. (https://doi.org/10.1161/HYPERTENSIONAHA.107.091512)

Baschat AA 2011 Neurodevelopment following fetal growth restriction and its relationship with antepartum parameters of placental dysfunction. Ultrasound in Obstetrics and Gynecology 37 501-514. (https://doi.org/10.1002/uog.9008)

Bole-Feysot C, Goffin V, Edery M, Binart N \& Kelly PA 1998 Prolactin (PRL) and its receptor: actions, signal transduction pathways and phenotypes observed in PRL receptor knockout mice. Endocrine Reviews 19 225-268. (https://doi.org/10.1210/ edrv.19.3.0334)

Braunstein GD, Rasor JL, Engvall E \& Wade ME 1980 Interrelationships of human chorionic gonadotropin, human placental lactogen, and pregnancy-specific beta 1-glycoprotein throughout normal human gestation. American Journal of Obstetrics and Gynecology 138 1205-1213. (https://doi.org/10.1016/s00029378(16)32793-4)

Grattan DR 2001 The actions of prolactin in the brain during pregnancy and lactation. Progress in Brain Research 133 153-171. (https://doi. org/10.1016/s0079-6123(01)33012-1)

Grattan DR 201560 YEARS OF NEUROENDOCRINOLOGY: The hypothalamo-prolactin axis. Journal of Endocrinology 226 T101-T122. (https://doi.org/10.1530/JOE-15-0213)

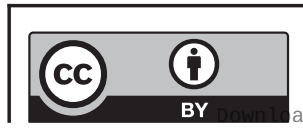

This work is licensed under a Creative Commons Attribution 4.0 International License. 
Grattan DR \& Kokay IC 2008 Prolactin: a pleiotropic neuroendocrine hormone. Journal of Neuroendocrinology 20 752-763. (https://doi. org/10.1111/j.1365-2826.2008.01736.x)

Grattan DR \& Le Tissier P 2015 Hypothalamic control of prolactin secretion, and the multiple reproductive functions of prolactin. In Knobil and Neill's Physiology of Reproduction, 4th ed., pp. 469-526. Eds TM Plant \& AJ Zeleznik. USA: Academic Press. (https//doi.org/ 10.1016/B978-0-12-397175-3.00012-0)

Handwerger S 1991 Clinical counterpoint: the physiology of placental lactogen in human pregnancy. Endocrine Reviews 12 329-336. (https:// doi.org/10.1210/edrv-12-4-329)

Hauth JC, Parker Jr CR, MacDonald PC, Porter JC \& Johnston JM 1978 A role of fetal prolactin in lung maturation. Obstetrics and Gynecology 51 81-88. (https://doi.org/10.1097/00006254-19780800000002)

Janssen AB, Tunster SJ, Heazell AE \& John RM 2016 Placental PHLDA2 expression is increased in cases of fetal growth restriction following reduced fetal movements. BMC Medical Genetics 1717. (https://doi.org/10.1186/s12881-016-0279-1)

Jensen AB, Tunster SJ \& John RM 2014 The significance of elevated placental PHLDA2 in human growth restricted pregnancies. Placenta 35 528-532. (https://doi.org/10.1016/j.placenta.2014.04.018)

John RM 2013 Epigenetic regulation of placental endocrine lineages and complications of pregnancy. Biochemical Society Transactions $\mathbf{4 1}$ 701-709. (https://doi.org/10.1042/BST20130002)

Knofler M 2010 Critical growth factors and signalling pathways controlling human trophoblast invasion. International Journal of Developmental Biology 54 269-280. (https://doi.org/10.1387/ ijdb.082769mk)

Lagerstrom M, Bremme K \& Eneroth P 1990 Maternal serum levels of estriol, prolactin, human placental lactogen and chorionic gonadotrophin related to fetal sex in normal and abnormal pregnancies. Gynecologic and Obstetric Investigation 30 198-203. (https://doi.org/10.1159/000293269)

Lee CK, Kang SG, Lee JT, Lee SW, Kim JH, Kim DH, Son BC, Kim KH, Suh CH, Kim SY, et al. 2015 Effects of perfluorooctane sulfuric acid on placental PRL-family hormone production and fetal growth retardation in mice. Molecular and Cellular Endocrinology 401 165-172. (https://doi.org/10.1016/j.mce.2014.10.026)

Liao S, Vickers MH, Taylor RS, Jones B, Fraser M, McCowan LM, Baker PN \& Perry JK 2016 Human placental growth hormone is increased in maternal serum at 20 weeks of gestation in pregnancies with large-for-gestational-age babies. Growth Factors 34 203-209. (https://doi.org/10.1080/08977194.2016.1273223)

Lindqvist PG \& Molin J 2005 Does antenatal identification of small-forgestational age fetuses significantly improve their outcome? Ultrasound in Obstetrics and Gynecology 25 258-264. (https://doi.org/10.1002/ uog.1806)

Mannik J, Vaas P, Rull K, Teesalu P, Rebane T \& Laan M 2010 Differential expression profile of growth hormone/chorionic somatomammotropin genes in placenta of small- and large-forgestational-age newborns. Journal of Clinical Endocrinology and Metabolism 95 2433-2442. (https://doi.org/10.1210/jc.2010-0023)

McCowan LM, Roberts CT, Dekker GA, Taylor RS, Chan EH, Kenny LC, Baker PN, Moss-Morris R, Chappell LC, North RA, et al. 2010 Risk factors for small-for-gestational-age infants by customised birthweight centiles: data from an international prospective cohort study. BJOG 117 1599-1607. (https://doi $\operatorname{org} / 10.1111 / j .1471-0528.2010 .02737 . x)$

McCowan LM, Thompson JM, Taylor RS, North RA, Poston L, Baker PN, Myers J, Roberts CT, Dekker GA, Simpson NA, et al. 2013 Clinical prediction in early pregnancy of infants small for gestational age by customised birthweight centiles: findings from a healthy nulliparous cohort. PLOS ONE 8 e70917. (https://doi. org/10.1371/journal.pone.0070917)

Newbern D \& Freemark M 2011 Placental hormones and the control of maternal metabolism and fetal growth. Current Opinion in Endocrinology, Diabetes, and Obesity 18 409-416. (https://doi. org/10.1097/MED.0b013e32834c800d)

PMMRC 2018 Telfth Annual Report of the Perinatal and Maternal Mortality Review Committee: Reporting Mortality 2016. Wellington: Health Quality and Safety Commission.

Pullano JG, Cohen-Addad N, Apuzzio JJ, Ganesh VL \& Josimovich JB 1989 Water and salt conservation in the human fetus and newborn. I. Evidence for a role of fetal prolactin. Journal of Clinical Endocrinology and Metabolism 69 1180-1186. (https://doi.org/10.1210/ jcem-69-6-1180)

Roex A, Nikpoor P, van Eerd E, Hodyl N \& Dekker G 2012 Serial plotting on customised fundal height charts results in doubling of the antenatal detection of small for gestational age fetuses in nulliparous women. Australian and New Zealand Journal of Obstetrics and Gynaecology 52 78-82. (https://doi.org/10.1111/j.1479828X.2011.01408.x)

Romero R, Erez O, Maymon E, Chaemsaithong P, Xu Z, Pacora P, Chaiworapongsa T, Done B, Hassan SS \& Tarca AL 2017 The maternal plasma proteome changes as a function of gestational age in normal pregnancy: a longitudinal study. American Journal of Obstetrics and Gynecology 217 67.e1-67.e21. (https://doi.org/10.1016/j. ajog.2017.02.037)

Sorenson RL \& Brelje TC 1997 Adaptation of islets of Langerhans to pregnancy: beta-cell growth, enhanced insulin secretion and the role of lactogenic hormones. Hormone and Metabolic Research 29 301-307. (https://doi.org/10.1055/s-2007-979040)

Stefanoska I, Jovanovic Krivokuca M, Vasilijic S, Cujic D \& Vicovac L 2013 Prolactin stimulates cell migration and invasion by human trophoblast in vitro. Placenta 34 775-783. (https://doi. org/10.1016/j.placenta.2013.06.305)

Trott JF, Schennink A, Petrie WK, Manjarin R, VanKlompenberg MK \& Hovey RC 2012 Triennial Lactation Symposium: Prolactin: the multifaceted potentiator of mammary growth and function. Journal of Animal Science 90 1674-1686. (https:// doi.org/10.2527/jas.2011-4682)

Tunster SJ, Creeth HDJ \& John RM 2016 The imprinted Phlda2 gene modulates a major endocrine compartment of the placenta to regulate placental demands for maternal resources. Developmental Biology 409 251-260. (https://doi.org/10.1016/j.ydbio.2015.10.015)

Tyson JE, Hwang P, Guyda H \& Friesen HG 1972 Studies of prolactin secretion in human pregnancy. American Journal of Obstetrics and Gynecology 113 14-20. (https://doi.org/10.1016/00029378(72)90446-2)

Winters AJ, Colston C, MacDonald PC \& Porter JC 1975 Fetal plasma prolactin levels. Journal of Clinical Endocrinology and Metabolism $\mathbf{4 1}$ 626-629. (https://doi.org/10.1210/jcem-41-3-626)

Wright J, Morse K, Kody S \& Francis A 2006 Audit of fundal height measurement plotted on customised growth charts. MIDIRS Midwifery Digest 16 341-345.

Received in final form 17 August 2021

Accepted 10 September 2021

Accepted Manuscript published online 13 September 2021 https://raf.bioscientifica.com

https://doi.org/10.1530/RAF-21-0020 (c) 2021 The authors Published by Bioscientifica Ltd

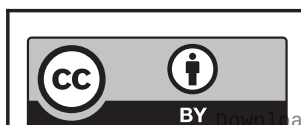

This work is licensed under a Creative Commons Attribution 4.0 International License. 